NBER WORKING PAPER SERIES

\title{
REMEDIES FOR PRICE OVERCHARGES: THE DEADWEIGHT LOSS OF COUPONS AND DISCOUNTS
}

\author{
A. Mitchell Polinsky \\ Daniel L. Rubinfeld \\ Working Paper 10162 \\ http://www.nber.org/papers/w10162
}

\section{NATIONAL BUREAU OF ECONOMIC RESEARCH 1050 Massachusetts Avenue Cambridge, MA 02138}

December 2003

Polinsky's research was supported by the John M. Olin Program in Law and Economics at Stanford Law School. We received helpful comments from Ian Ayres, Jonathan Baker, Howard Chang, Richard Craswell, Deborah Hensler, Steven Shavell, and Kathryn Spier, and valuable research assistance from Paul Riskind. We also benefited from conversations with Fred Gramlich and Joseph Mulholland. The views expressed herein are those of the authors and not necessarily those of the National Bureau of Economic Research.

(C)2003 by A. Mitchell Polinsky and Daniel L. Rubinfeld. All rights reserved. Short sections of text, not to exceed two paragraphs, may be quoted without explicit permission provided that full credit, including (C) notice, is given to the source. 
Remedies for Price Overcharges: The Deadweight Loss of Coupons and Discounts

A. Mitchell Polinsky and Daniel L. Rubinfeld

NBER Working Paper No. 10162

December 2003

JEL No. D18, D42, K21, L12, L41

\section{ABSTRACT}

This article evaluates two different remedies for consumers who have been injured by a price overcharge on the sale of a good. Under a coupon remedy, injured consumers are awarded coupons that can be used for a limited period of time to purchase the good at a price below that which prevails after the overcharge has been eliminated, that is, below the competitive price. Under a discount remedy, any consumer, without proof of injury, may purchase the good for a limited period of time at a price that is set below the competitive price. Both remedies generally cause consumers to buy an excessive amount of the good during the remedy period. Under the coupon remedy only a subset of consumers are affected in this way (those holding a relatively high number of coupons), while under the discount remedy all consumers are affected. We show nonetheless that the resulting deadweight loss could be lower under the discount remedy. We also consider how the deadweight loss changes when the length of the remedy period is increased - by extending the expiration date for the use of coupons or by employing a lower discount for a longer period of time. The deadweight loss may or may not decline under the coupon remedy, though it does decline under the discount remedy. In neither case, however, does it go to zero in the limit.
A. Mitchell Polinsky Stanford Law School Stanford University Stanford, CA 94305 and NBER polinsky@stanford.edu
Daniel L. Rubinfeld Department of Economics University of California, Berkeley Berkeley, CA 94720-3880 rubinfeld@law.berkeley.edu 


\section{Introduction}

In many lawsuits alleging that prices are improperly high, the remedy takes the form of awarding injured consumers coupons that can be used to purchase the good at a price below that which prevails after the overcharge has been eliminated. Such coupons usually have an expiration date and are not transferable or are limited in their transferability. ${ }^{1}$ For example, in 1994 passengers who had traveled on major U.S. airlines between January 1988 and June 1992 received coupons with a total face value of approximately $\$ 400$ million that could be applied toward their cost of subsequent flights; these coupons expired after three years and could be transferred only to immediate family members or to someone designated in advance.

Although coupon remedies of this sort have been widely used, commentators generally are highly critical of them. The dominant reason is that coupons are thought to facilitate settlements between the lawyers representing the class of consumers and the defendant that are not in the interests of the consumers. Because the lawyers' compensation usually is based in large part on the value of the remedy to the class, the lawyers will try to convince the judge who has to approve the settlement that the coupons are worth close to their face value, even though many, if not most, of the coupons will not actually be used. ${ }^{2}$ If the lawyers succeed, they may be well rewarded, while the effective cost to the defendant of the settlement will be relatively low; and consumers obtain a remedy that is of relatively little value.

Our analysis of coupon remedies focuses on an entirely different criticism - even if consumers are adequately compensated by the award of coupons, the coupons can significantly

\footnotetext{
${ }^{1}$ Even when transfers are permitted, markets for coupons may not arise because of transaction costs.

${ }^{2}$ According to Gramlich (1986, p. 274), the average coupon redemption rate for consumer and corporate plaintiffs combined is 26.3 percent. For consumer plaintiffs alone, it is 13.1 percent. 
distort their consumption decisions. ${ }^{3}$ This point is most easily explained by considering a variant of the coupon remedy - a discount off the competitive price for all consumers of the product. For example, if price fixing results in the price being set at $\$ 65$ for some period of time when the competitive price would have been $\$ 50$, the price would be discounted to some price below $\$ 50$ for a comparable period of time after the price fixing is stopped. Our concern is with the resulting inefficiency during the remedy period: whereas the price overcharge causes consumers to buy too little of the product relative to efficient consumption, the discount causes them to buy too much. ${ }^{4}$

A coupon remedy creates a similar consumption inefficiency. To see why, suppose that individual demand for a product (for example, airline travel) is stochastic from period to period. Consider a consumer whose demand was "high" in the injury period, and who therefore obtains a substantial number of coupons, but whose demand is "low" in the remedy period, during which the coupons must be redeemed. That consumer will be induced to buy a socially excessive amount of the good during the remedy period because the availability of the coupons effectively lowers the price of the good. ${ }^{5}$ But if the consumer's demand is high again in the remedy period, there will not be a distortion. This is because, if his demand remains high during the remedy period, he will purchase more of the good at the competitive price than he did during the injury

\footnotetext{
${ }^{3}$ The distorting effect of coupons on consumption decisions has not been analyzed previously. Other discussions of coupon remedies have focused on different points. See note 6 below.

${ }^{4}$ To our knowledge, a pure discount remedy has not been used, though coupon remedies in which access to coupons is readily available are essentially equivalent to what we are referring to as a discount remedy. Gramlich (1986, p. 275) provides two examples of coupon settlements in which the coupons were widely distributed: "In Fisher, coupons were mailed out to all area households irrespective of prior purchase. . . . [I]n Bi-Rite, ... postsettlement discounts were freely available to all who visited defendant's grocery stores..." demand curve.

${ }^{5}$ To be precise, this conclusion holds only if the high demand curve is sufficiently higher than the low
} 
period at the marked-up price, resulting in his running out of coupons. Consequently, all of his marginal purchases during the remedy period will be at the competitive price. Obviously, one must also account for the possibility that the consumer's demand is low during the injury period and the remedy period, but it is clear that there is some probability that a coupon remedy also will distort consumption.

The preceding discussion seems to suggest that, as between coupons and discounts, coupons are preferable because they only distort the consumption decisions of a fraction of the consumers who buy in the remedy period, whereas discounts distort the behavior of all such consumers. It does not follow, however, that discounts are less desirable than coupons. Indeed, we will demonstrate that the deadweight loss of discounts often is less than that of coupons. The explanation, which we elaborate upon below, stems from the following observations. To make consumers as a class whole, the face value of the coupon must be greater than the magnitude of the discount. In part, this is because coupons are underinclusive (consumers who would have bought the product at the competitive price but who did not buy it at the marked-up price do not receive any coupons), while discounts are overinclusive (consumers who would not have bought the product at the competitive price might buy it at the discounted price). Hence, even though a greater number of consumers make distorted decisions under the discount remedy, the resulting deadweight loss might be lower because the magnitude of the price distortion is less under the discount remedy. This conclusion is reinforced by the fact that the deadweight loss from a price distortion increases more than proportionally with the magnitude of the distortion.

We also consider the desirability of extending the period of time during which the remedies are applicable. Under the discount remedy, this means using a lower discount for a longer period, while guaranteeing that the present value of the benefits conferred on consumers 
makes them whole. Similarly, under the coupon remedy, this means lowering the face value of the coupons and extending their expiration date. We show that the present value of the deadweight loss from the discount remedy necessarily declines if the remedy is extended from one to two periods, but that the corresponding loss from the coupon remedy could rise. We also demonstrate that the deadweight loss from discounts and coupons does not go to zero as the number of remedy periods increases without bound. At least in the case of coupons, this result is unexpected because one would think that if coupons could be used forever, they are equivalent to cash and therefore non-distorting.

Our article is organized as follows. Section II presents the basic framework used to analyze coupons and discounts. Section III derives the deadweight loss of the coupon remedy when there is one remedy period (equal in length to the injury period). Section IV undertakes the corresponding analysis for the discount remedy. Section V compares the two remedies. Section VI extends the analysis to multiple remedy periods. Section VII concludes with a discussion of the merits of the coupon and discount remedies relative to a cash remedy. ${ }^{6}$

\section{Basic Framework}

The cost of producing the good at issue is assumed to be constant per unit, with no fixed costs. During the injury period, the producer wrongfully charges more than the competitive

\footnotetext{
${ }^{6} \mathrm{We}$ are aware of only three analytical studies of coupon remedies. Gramlich (1986) discusses several rationales for using coupons rather than cash as a remedy and, in an unpublished appendix, formally analyzes the effects of coupons on the market equilibrium under different assumptions about, among other things, the existence of nondefendant sellers, the cost of production, and market power. Borenstein (1996) examines how firms with market power raise prices in response to the availability of coupons applicable to their goods, and proposes a timeunlimited coupon remedy that mitigates this effect (see also note 7 below). Gramlich (2003) evaluates how the form of the coupon remedy — whether it is a fixed discount, a percentage discount, or the right to buy at a fixed price affects the benefits obtained by consumers, the profits lost by the defendant, and the efficiency (total surplus) of the
} 
price - that is, more than the marginal cost of production. We assume for simplicity that after the price overcharge has been stopped, the competitive price will prevail, aside from the effect of any remedy. ${ }^{7}$ Let

$$
\begin{aligned}
& c=\text { constant marginal cost of production; and } \\
& m=\text { price markup during the injury period. }{ }^{8}
\end{aligned}
$$

Thus, the price during the injury period is $c+m$, and the price thereafter would be $c$ if there were no remedy.

We assume that the demand for the product is linear and stochastic. In each period a consumer may have "low" demand or "high" demand. The individual's demand curve is

$$
q=a_{i}-b P
$$

where $i=H$ if demand is high and $i=L$ if demand is low $\left(a_{H}>a_{L}\right)$. Demand is assumed to be independent from period to period. Let

$\theta=$ probability that demand is low.

The population of consumers is normalized to be unity. Thus, we will refer to an individual consumer and the class of consumers interchangeably.

market when firms have market power. Coupon remedies also are discussed informally in several law review articles. See, for example, Note (1996), Miller and Singer (1997), and Leslie (2002).

${ }^{7}$ We make this assumption in order to focus on the effects of the remedies on consumption distortions. It might be justified on the basis that the ex-remedy price (the price that would be paid in the absence of a coupon or discount) is set by competitive suppliers who are not subject to any remedy. Borenstein (1996, pp. 386-92), however, shows that even in a competitive setting the ex-coupon price may be affected by the existence of coupons. In any case, the assumption that the competitive price would prevail during the remedy period is not essential to our analysis of the deadweight losses of the remedies. Were the ex-remedy price higher than the competitive price, the coupon value and the discount would need to be that much greater in order to make the class whole relative to the competitive outcome, in which case the deadweight losses would be the same as we derive.

${ }^{8}$ For our purposes, it is not essential that the markup be that which would be chosen by a profitmaximizing monopolist. Nonetheless, our examples utilize markups that are no greater than the monopoly markup. 
Next consider the losses suffered by consumers during the injury period. The consumption decision for a consumer whose demand is $a_{i}-b P$ in the injury period is shown in

Figure 1. ${ }^{9}$ The loss of consumer surplus due to the price markup is the sum of the areas A and B

in Figure 1, which can be expressed as

$$
\left(a_{i}-b(c+m)\right) m+.5 b m^{2} .
$$

Let

$$
K=\text { the expected consumer surplus loss during the injury period. }
$$

Hence,

$$
\begin{gathered}
K=\theta\left[\left(a_{L}-b(c+m)\right) m+.5 b m^{2}\right]+(1-\theta)\left[\left(a_{H}-b(c+m)\right) m+.5 b m^{2}\right] \\
=\left[\theta a_{L}+(1-\theta) a_{H}\right] m-b c m-.5 b m^{2} .
\end{gathered}
$$

In the next two sections, we derive the deadweight loss of the coupon and discount remedies assuming that the benefit conferred by each remedy equals the loss suffered by consumers during the injury period (3), so that consumers are made whole. ${ }^{10}$

\section{The Deadweight Loss of a Coupon Remedy}

Suppose consumers who bought the good at the marked-up price are given coupons equal in number to the units of the good that they purchased during the injury period. The coupons

\footnotetext{
${ }^{9}$ We assume that both types of individuals — low demanders and high demanders — purchase positive output at the injury period's price of $c+m$.

${ }^{10}$ As noted in the introduction, coupons generally are underinclusive - some consumers who were injured will not receive coupons - while discounts are overinclusive - some consumers who were not injured will benefit from the discount. Thus, the assumption that consumers are made whole is applied on a class-wide basis, not on an individual-by-individual basis. It should also be observed that our conclusions only depend on the remedies conferring the same benefits to consumers, not necessarily that they make consumers whole. The assumption that the remedies provide benefits equal to harm is, however, a natural one to make.
} 
FIGURE 1

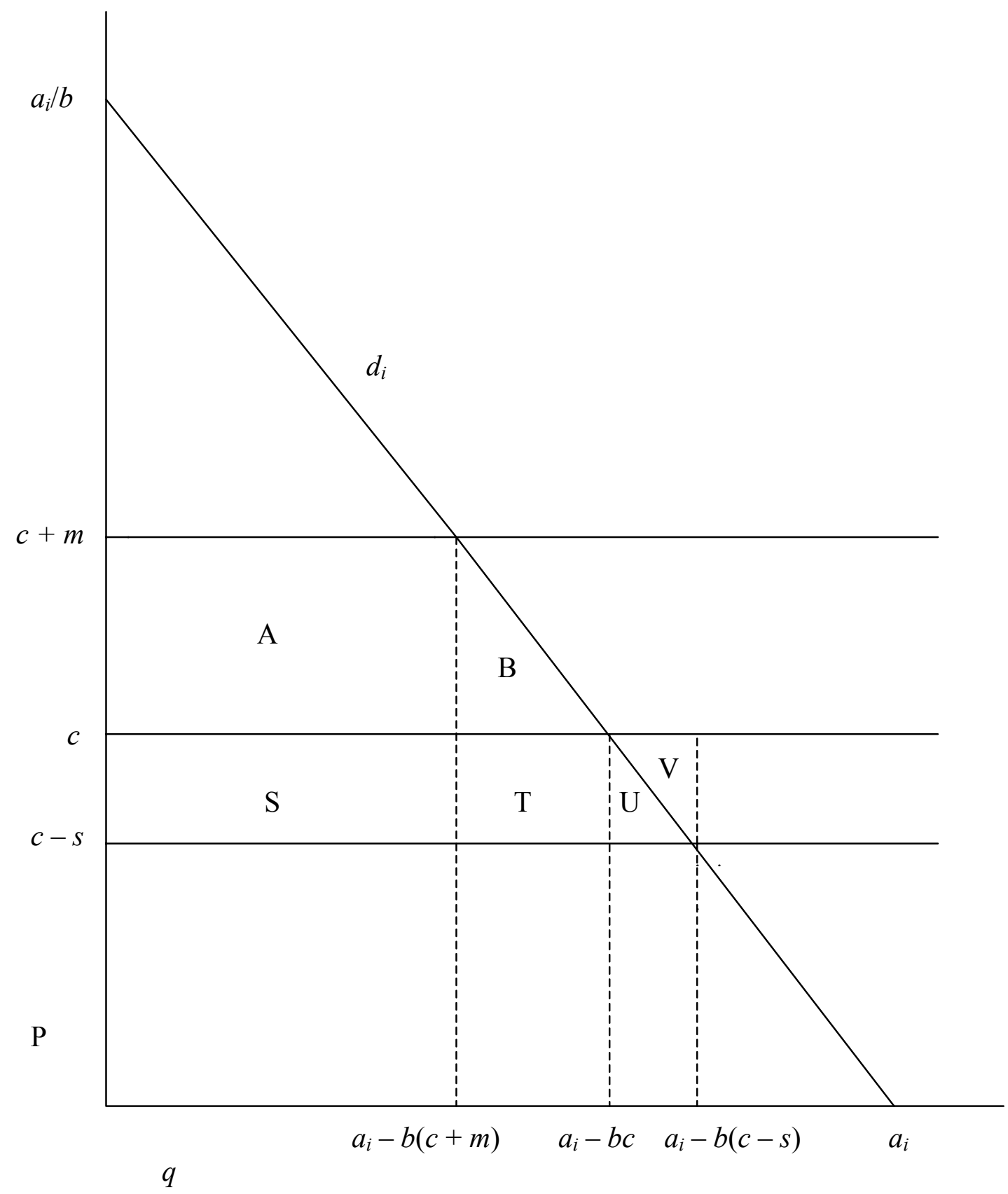


then can be used to buy the good during the remedy period at the competitive price $c$ less the face value of the coupon. ${ }^{11}$ Let

$r=$ face value of each coupon.

There are four cases to consider, depending on whether an individual's demand is low or high in the injury period and low or high in the remedy period.

(a) Low demand in the injury period; low demand in the remedy period. At price $c+m$ in the injury period, an individual with low demand will purchase $a_{L}-b(c+m)$ units of the good; see Figure 1. He will thus receive that many coupons. If that person had low demand again in the remedy period, he would buy $a_{L}-b c$ units of the good if the price were the competitive price $c$. Since $a_{L}-b c>a_{L}-b(c+m)$, he will have insufficient coupons to use for these purchases, implying that at the margin he will face the price $c$ and buy $a_{L}-b c$ units of the good. Thus, the value to him of the coupons is $\left[a_{L}-b(c+m)\right] r$. In other words, he values the coupons at their face value.

(b) Low demand in the injury period; high demand in the remedy period. As in case (a), the individual will have insufficient coupons to buy the quantity of the good he would want at the price $c$. Hence, he will buy $a_{H}-b c$ units of the good in the remedy period and value the coupons again at $\left[a_{L}-b(c+m)\right] r$.

(c) High demand in the injury period; low demand in the remedy period. The individual will receive $a_{H}-b(c+m)$ coupons. We assume that when he then has low demand in the

\footnotetext{
${ }^{11}$ Although producers will be losing money on the sale of goods purchased with coupons, we assume for reasons outside of our model that they will not exit the industry. Such reasons might include the long-term reputational interests of firms and the transactions costs associated with exit and re-entry.
} 
remedy period, he will have more than enough coupons to apply to the purchase of the quantity he would demand if he faced the competitive price $c$. In other words,

$$
a_{H}-b(c+m)>a_{L}-b c .
$$

If (4) did not hold, there would be no deadweight loss under the coupon approach.

A version of case (c) is illustrated in Figure 2; here the individual uses all of his coupons and would have used more if more were available (since the height of his demand curve $D_{L}$ exceeds $c-r$ at the point at which he runs out of coupons). Another possibility is that the individual has a surplus of coupons and buys $a_{L}-b(c-r)$ units of the good in the remedy period (this quantity corresponds to the intersection of the low demand curve $d_{L}$ and the price line $c-r$ ). The value of the coupons in case (c) is the sum of the areas E and F in Figure 2, which can expressed as

$$
\left(a_{L}-b c\right) r+\left[r-\left(x^{\prime} / 2 b\right)\right] x^{\prime},
$$

where

$$
\begin{aligned}
& x=\text { number of coupons the individual obtains in excess of } a_{L}-b c ; \text { and } \\
& x^{\prime}=\min (x, b r) .
\end{aligned}
$$

The first term in (5) corresponds to area $\mathrm{E}$ in Figure 2, while the second term corresponds to area F. The reason $x$ ' is defined as the minimum of $x$ and $b r$ is to allow for the two possibilities in case (c) - that the individual might want more coupons $(x<b r)$ or that he has at least as many as he would ever use $(x \geq b r)$.

(d) High demand in the injury period; high demand in the remedy period. This case is analogous to case (a). The individual will receive $a_{H}-b(c+m)$ coupons, buy $a_{H}-b c$ units of the good in the remedy period, and value his coupons at $\left[a_{H}-b(c+m)\right] r$. 
FIGURE 2

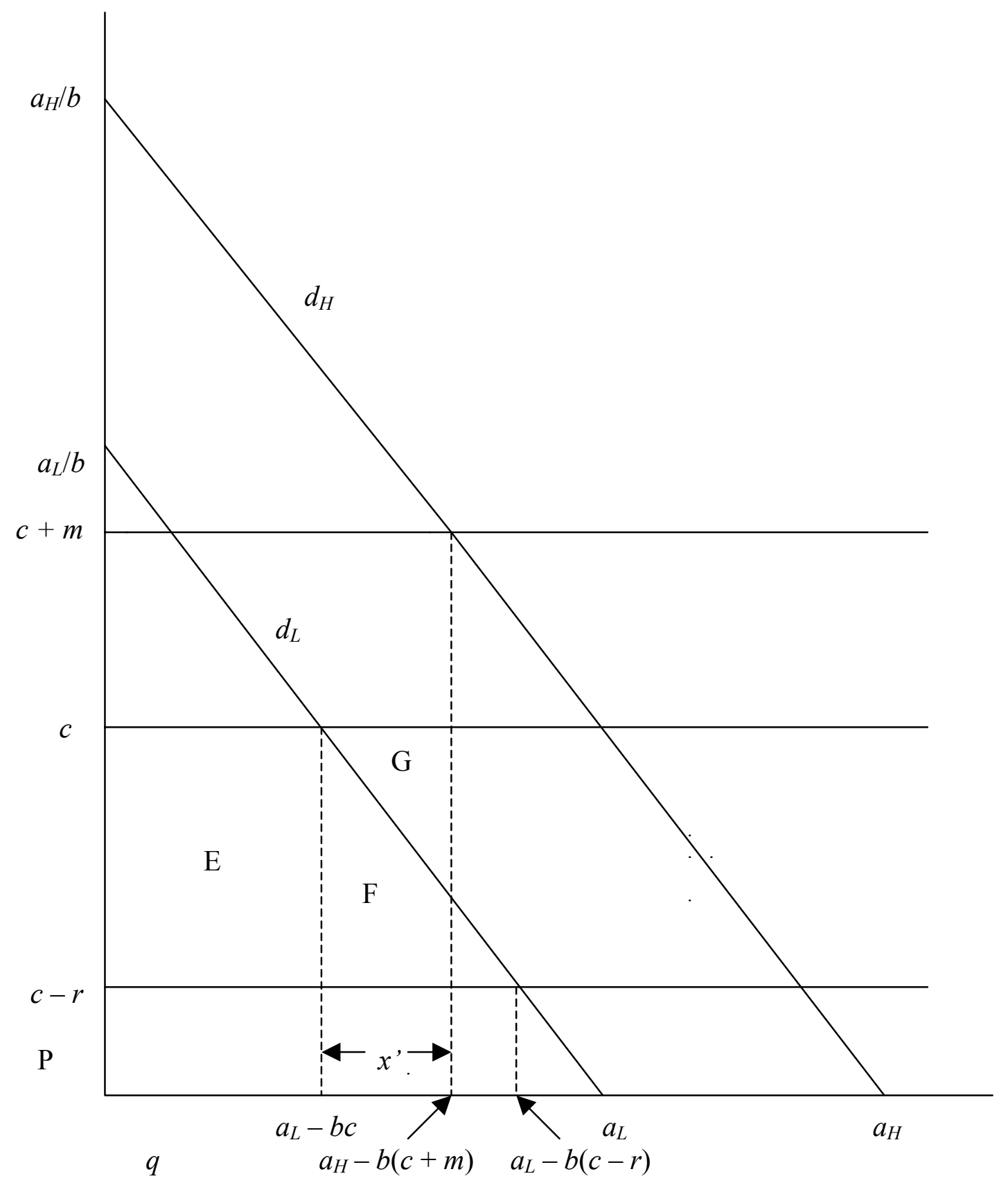


Given the preceding, the expected value of the coupons to the class of victims is:

$$
\begin{gathered}
\theta\left[a_{L}-b(c+m)\right] r \\
+(1-\theta)\left\{\theta\left[\left(a_{L}-b c\right) r+\left[r-\left(x^{\prime} / 2 b\right)\right] x^{\prime}\right]+(1-\theta)\left[a_{H}-b(c+m)\right] r\right\} .
\end{gathered}
$$

The first term in (6) corresponds to cases (a) and (b), and the second term to cases (c) and (d).

To determine the coupon value $r$ that makes the class whole, set (6) equal to the injury to the class (3) and solve for $r .^{12}$ There are two possibilities to consider, corresponding to the two possibilities discussed in case (c). ${ }^{13}$ If the individual has a shortage of coupons $(x<b r)$, then $r$ can be solved directly from

$$
\begin{gathered}
\left\{\theta\left[a_{L}-b(c+m)\right]+(1-\theta) \theta\left(a_{L}-b c\right)+(1-\theta) \theta x^{\prime}+(1-\theta)^{2}\left[a_{H}-b(c+m)\right]\right\} r \\
-\left[(1-\theta) \theta\left(x^{\prime}\right)^{2} / 2 b\right]-K=0,
\end{gathered}
$$

where $x^{\prime}=a_{H}-a_{L}-b m$ and $K$ is given by (3). If the individual has a surplus of coupons ( $x \geq$ $b r), r$ can be solved from the following quadratic equation:

$$
\begin{gathered}
.5(1-\theta) \theta b r^{2} \\
+\left\{\theta\left[a_{L}-b(c+m)\right]+(1-\theta) \theta\left(a_{L}-b c\right)+(1-\theta)^{2}\left[a_{H}-b(c+m)\right]\right\} r-K=0 .
\end{gathered}
$$

The coupon value $r$ determined by (7) or (8) exceeds the markup in the injury period $m$. This is because coupons must compensate individuals not only for the markup over the competitive price for the units of the good purchased during the injury period, but also for the harm suffered because fewer units were purchased at the higher price. In terms of Figure 1, if the coupon value $r$ equaled the markup $m$, coupons would compensate individuals for the harm corresponding to area A, but not area $\mathrm{B}$. To compensate for both areas, $r$ must exceed $m$. This

\footnotetext{
${ }^{12} \mathrm{We}$ assume that the parameter values are such that the resulting value of $r$ is less than the marginal cost $c$, so that the post-coupon price $c-r$ is positive.

${ }^{13}$ As will be seen, which is applicable depends on the value of $r$.
} 
conclusion is reinforced by the observation that in case (c), some of the coupons are valued at less than their face value. Specifically, referring to Figure 2, all coupons used beyond $a_{L}-b c$ are valued at less than $r$. Indeed, if there is a surplus of coupons, some coupons are valued at zero.

Finally, consider the deadweight loss of the coupon remedy. As seen above, in cases (a), (b), and (d), the number of coupons an individual is awarded is less than the number of units of the good he would buy at the competitive price in the remedy period. Consequently, his consumption is not distorted in these cases. In case (c), however, he is induced to purchase more units of the good as a result of the availability of the coupons. The resulting deadweight loss corresponds to area $\mathrm{G}$ in Figure 2, which equals $.5\left(x^{\prime}\right)^{2} / b$. Hence, the expected deadweight loss under the coupon remedy is

$$
.5 \theta(1-\theta)\left(x^{\prime}\right)^{2} / b^{14}
$$

\section{The Deadweight Loss of a Discount Remedy}

Now suppose that the remedy consists of allowing all consumers (whether harmed or not) to purchase as much of the good as they want at some price less than the competitive price $c$. Let $s=$ discount below the competitive price.

Then the price in the remedy period is $c-s$.

Referring to Figure 1, an individual with demand curve $d_{i}$ in the remedy period will purchase $a_{i}-b(c-s)$ units of the good. The value of the discount remedy to this individual is the sum of the areas $\mathrm{S}, \mathrm{T}$, and $\mathrm{U}$ in Figure 1, which equals $\left(a_{i}-b c\right) s+.5 b s^{2}$. Thus, the expected

\footnotetext{
${ }^{14}$ Gramlich (1986, pp. 267-68) observes that if the ex-coupon price in the remedy period is above marginal cost, then coupons might actually improve consumption decisions by effectively lowering the price. He also notes that "[i]f the value of the scrip [coupons] exceeds the markup above marginal cost, an offsetting inefficiency of overconsumption can occur."
} 
value of the discount remedy to the class of consumers, given the probability of demand being low or high, is:

$$
\theta\left[\left(a_{L}-b c\right) s+.5 b s^{2}\right]+(1-\theta)\left[\left(a_{H}-b c\right) s+.5 b s^{2}\right] .
$$

To determine the discount that makes the class whole, set (10) equal to the injury to the class (3) and solve for $s .{ }^{15}$ The resulting quadratic equation in $s$ is:

$$
.5 b s^{2}+\left[\theta a_{L}+(1-\theta) a_{H}-b c\right] s-K=0 .
$$

The discount $s$ that solves (11) is less than the markup in the injury period $m$. This follows from the observation that consumers buy more of the good at the discounted price than they did at the marked-up price. Consequently, if the discount equaled the markup, consumers would gain more from the discount than they loss from the markup. This is easy to see in Figure 1. The gain from the discount is the sum of the areas $\mathrm{S}, \mathrm{T}$, and $\mathrm{U}$. The harm from the markup is the sum of the areas A and B. If $s$ were to equal $m$, then $\mathrm{S}$ and $\mathrm{A}$ would be of identical size and T would exceed B; thus the gain would exceed the loss. To avoid overcompensating consumers, the discount $s$ must be less than the markup $m$.

Finally, consider the deadweight loss of the discount remedy. It is clear from Figure 1 that this loss corresponds to area $\mathrm{V}$, which equals $.5 b s^{2}$. Note, moreover, that this loss is the same for individuals with low demand and high demand. Thus, the deadweight loss under the discount remedy is

$$
.5 b s^{2}
$$

${ }^{15}$ That the resulting value of $s$ is such that the post-discount price $c-s$ is positive follows from the assumption in note 12 above that $c-r>0$ and the result in the next paragraph that $s<m$ (since $r>m$ ). 


\section{The Coupon Remedy Versus the Discount Remedy}

In this section we compare the deadweight loss of the coupon remedy to that of the discount remedy. As noted in the introduction, either could be preferable. If the coupon value equaled the discount, then the coupon remedy would have a lower deadweight loss because only a fraction of the individuals who receive coupons will have their consumption decision distorted by the use of the coupons (those in case (c) in Section III), whereas everyone's consumption decision will be distorted if there is a discount. However, as seen in Sections III and IV, to make the victim class whole, the coupon value must exceed the markup, whereas the discount must be less than the markup. Consequently, even though fewer individuals have their consumption decisions distorted by the coupon remedy, the magnitude of the distortion for each individual is greater. Since the deadweight loss increases more than proportionally with the magnitude of the price distortion, it is possible that the deadweight loss under the coupon remedy will exceed that under the discount remedy. Of course, the converse also is possible.

We will illustrate these conclusions with a numerical example. Let $a_{L}=\$ 350, a_{H}=$ $\$ 750, b=5, c=\$ 50, m=\$ 15$, and $\theta=.7$. Given these assumptions, the harm suffered by the class during the injury period is $\$ 2,737.50$. To make the victim class whole using coupons would require a coupon value of $\$ 29.65$, nearly double the markup. ${ }^{16}$ The resulting deadweight loss when coupons are used is $\$ 461.63$, with 21 percent of the population (that is, the fraction (1 $-\theta) \theta$ ) having their consumption decisions distorted. Alternatively, to make the victim class whole using a discount remedy would require a discount of \$11.05, which would result in a

\footnotetext{
${ }^{16}$ In this example (and the one in the next paragraph), the individual has a surplus of coupons, so $r$ is determined by (8).
} 
deadweight loss of $\$ 305.51$. Thus, in this example, the discount remedy would be preferred to the coupon remedy, with a deadweight loss that is nearly 34 percent less.

The opposite result can be illustrated by changing $\theta$ from .7 to .2 , in which case the harm to the class is $\$ 5,737.50$. Then to make the victim class whole using coupons would require a coupon value of $\$ 19.08$, with a corresponding deadweight loss of $\$ 145.69$ (16 percent of the population's consumption decisions are distorted). To make the victim class whole using a discount remedy would require a discount of $\$ 12.70$, which would result in a deadweight loss of $\$ 403.26$. Now the coupon remedy would be preferred, with a deadweight loss nearly 64 percent less than that under the discount remedy. One reason that the change in $\theta$ made the coupon remedy relatively more attractive is that the percentage of the population whose consumption is distorted by the use of coupons has dropped from 21 percent in the previous example to 16 percent here. Note, too, that the face value of the coupon required to make the class whole declined significantly, from $\$ 29.65$ to $\$ 19.08$, thereby greatly reducing the magnitude of the distortion caused by the use of coupons.

\section{Multiple Remedy Periods}

In the preceding analysis, we implicitly assumed that there was one remedy period, equal in length to the period during which the harm occurred. In this section we consider the desirability of allowing the remedy to apply over multiple periods — by extending the expiration date for the use of the coupons or by employing a lower discount for a longer period of time.

Intuitively, one would expect that the deadweight loss associated with coupons would decline if the expiration date is extended because coupons would be more likely to be used for purchases that would be made anyway. Reinforcing this conclusion is the observation that, if 
consumers are given more flexibility about when they can use their coupons, the face value of the coupons can be lowered while still making consumers whole; everything else equal, this reduces the deadweight loss of coupons. Notwithstanding the preceding intuition, we show in subsection A below that the present value of the deadweight loss from coupons could decline or increase as the number of remedy periods increases. ${ }^{17}$ Moreover, even if the deadweight loss does decline, it does not go to zero as the number of remedy periods becomes arbitrarily large.

It also seems plausible that the deadweight loss of discounts would decline if the number of remedy periods increases, because a lower discount can be used. Employing a lower discount for a longer period of time is beneficial because the deadweight loss from a price distortion rises more than proportionally with the magnitude of the distortion. A countervailing consideration, however, is that, because of time discounting, the discount cannot be reduced proportionately as the number of periods increases. We demonstrate in subsection B that the present value of the deadweight loss of the discount remedy does decline as the number of remedy periods increases, but it does not go to zero.

\section{A. The Coupon Remedy}

To evaluate the coupon remedy when there are multiple remedy periods, it is first necessary to examine an individual's decision about how many coupons to use in each period. Because of the complexity of this analysis, we limit our discussion to two remedy periods.

As in the one-remedy-period analysis of coupons in Section III, there are four cases to consider. In three of these cases - (a), (b), and (d) - the individual's behavior is unaffected by the number of remedy periods because it is optimal for him to use all of his coupons in the first

\footnotetext{
${ }^{17}$ For reasons explained below, we do this just for the change from one to two remedy periods.
} 
remedy period. In these cases, as seen in Section III, he obtains the face value of the coupons. If he deferred using a coupon to a later remedy period, the coupon would be worth less to him, if only because of time discounting.

In case (c), however, in which the individual's demand is high in the injury period and low in the first (previously, only) remedy period, it may be optimal for him to defer using some of his coupons to the second remedy period. This is because, were he to use all of his coupons in the first remedy period, the value to him of his marginal coupons would be less than their face value. By deferring the use of some of his coupons, he might increase their value to him, even after time discounting. ${ }^{18}$ We assume that it $i$ s optimal for him to defer the use of some coupons to the second remedy period (otherwise, the two-remedy-period analysis would be uninteresting).

Two possibilities need to be considered in determining the individual's behavior in case (c). First suppose that the individual defers no more than $a_{L}-b c$ coupons to the second remedy period. If his demand in the second remedy period is low, he would consume $a_{L}-b c$ units of the good at the competitive price $c$. Consequently, his consumption would not be distorted. If his demand in the second remedy period is high, he would consume even more units of the good at the competitive price, so his consumption also would not be distorted. Thus, if the individual defers no more than $a_{L}-b c$ coupons to the second remedy period, there will not be a deadweight loss in the second remedy period. Because the face value of the coupon must be lower in the two-remedy-period analysis than in the one-remedy-period analysis (individuals benefit by deferring some coupons to the second remedy period), the deadweight loss from the distortion in

\footnotetext{
${ }^{18}$ The first coupons used in the second remedy period would be worth their face value, which, even after time discounting, might exceed the value of the marginal coupon in the first remedy period if all coupons are used then. If the time discount rate is low enough, using some coupons in the second remedy period clearly would be desirable.
} 
the first remedy period must be lower in the two-remedy-period analysis. Hence, with respect to the present possibility, the deadweight loss must be lower in the two-remedy-period analysis than in the one-remedy-period analysis.

The other possibility in case (c) is that the individual defers more than $a_{L}-b c$ coupons to the second remedy period. Then if his demand in the second remedy period is low, there will be a distortion in that period and a corresponding deadweight loss. If his demand in the second remedy period is high, however, there will not be a distortion because his total number of coupons, $a_{H}-b(c+m)$, is less than the number of units of the good, $a_{H}-b c$, that he would purchase at the competitive price. But since there now is, with some probability, a deadweight loss in the second remedy period, it is not obvious whether the present value of the deadweight loss in the two-remedy-period analysis is less than the deadweight loss in the one- period analysis.

To analyze the second possibility in case (c) more precisely, let $r(2)=$ face value of each coupon when there are two remedy periods;

$d=$ time discount rate;

$D=1 /(1+d)$

$x_{1}=$ number of coupons the individual uses in the first remedy period in excess of $a_{L}-b c$ if his demand is low;

$x_{2}=$ number of coupons the individual has available in the second remedy period in excess of $a_{L}-b c$;

$x_{2}{ }^{\prime}=\min \left(x_{2}, b r(2)\right) ;$ and

$U_{(c)}=$ the individual's discounted expected benefit from coupons conditional on his being in case (c). 
It will be useful to note that

$$
x_{2}=x-x_{1}-\left(a_{L}-b c\right)
$$

where, recall, $x$ is the number of coupons the individual obtains in excess of $a_{L}-b c$.

Analogously to the use of $x^{\prime}$ in Section III, $x_{2}$ ' is employed to allow for the possibilities that, if the individual's demand is low in the second remedy period, he might want more coupons $\left(x_{2}<\right.$ $\operatorname{br}(2))$ or that he has at least as many as he would ever use $\left(x_{2} \geq b r(2)\right)$.

The individual's discounted expected benefit in case (c) is

$$
\begin{gathered}
U_{(c)}=\left(a_{L}-b c\right) r(2)+\left[r(2)-x_{1} / 2 b\right] x_{1}+\theta D\left(a_{L}-b c\right) r(2) \\
+\theta D\left[r(2)-x_{2}^{\prime} / 2 b\right] x_{2}^{\prime}+(1-\theta) D\left(x-x_{1}\right) r(2) .
\end{gathered}
$$

The first term is the benefit to the individual in the first remedy period from using the first $a_{L}-$ $b c$ coupons, which are valued at their face value $r(2)$ because, even without coupons, he would have purchased this many units of the good at the competitive price $c$ (this benefit corresponds to area $\mathrm{E}$ in Figure 2). The second term is the benefit in the first remedy period from using the next $x_{1}$ coupons to purchase units of the good that would not have been purchased otherwise (area $\mathrm{F}$ in Figure 2). The third and fourth terms are the analogous benefits in the second remedy period if demand is low. The last term is the benefit in the second remedy period if demand is high, in which case all of the coupons used in the second remedy period are valued at their face value.

Maximizing (14) over $x_{1}$, and using (13) to substitute for $x_{2}$ when $x_{2}{ }^{\prime}=x_{2}$, yields the individual's optimal $x_{1}$ :

$$
x_{1} *=\left\{\begin{array}{l}
{\left[b(1-D) r(2)+\theta D\left(x-\left(a_{L}-b c\right)\right)\right] /[1+\theta D] \text { if } x_{2}<b r(2)} \\
{[1-(1-\theta) D] b r(2) \text { if } x_{2} \geq b r(2) .}
\end{array}\right.
$$


The discounted expected value of the coupons to the class of victims, taking into account all four cases, therefore is:

$$
\theta\left[a_{L}-b(c+m)\right] r(2)+(1-\theta)\left\{\theta U_{(c)} *+(1-\theta)\left[a_{H}-b(c+m)\right] r(2)\right\}
$$

where $U_{(c)} *$ is (14) evaluated at $x_{1}$ * given by (15). The first term in (16) corresponds to cases (a) and (b), and the second term to cases (c) and (d).

To determine the coupon value $r(2)$ that makes the class whole, set (16) equal to the injury to the class (3) and solve for $r(2)$. As in the one-period model, the resulting coupon value is the solution to a linear or quadratic equation (analogous to (7) and (8)). Because the present equations are similar in character, but much more complicated, we do not reproduce them here. ${ }^{19}$

Next consider the deadweight loss due to coupons in the two-remedy-period analysis. As in the one-remedy-period analysis, distorted consumption occurs only in case (c), when demand is high in the injury period and low in the first remedy period. But now, if the individual defers more than $a_{L}-b c$ coupons to the second remedy period and his demand is low again, consumption will be distorted then as well. Thus, the resulting deadweight loss in the tworemedy-period analysis is (assuming $x_{2}$ is positive)

$$
.5(1-\theta) \theta\left(x_{1}^{*}\right)^{2} / b+.5(1-\theta) \theta^{2} D\left(x_{2}{ }^{\prime} *\right)^{2} / b,
$$

where $x_{1} *$ is given by (15) and $x_{2}{ }^{*} *$ is $\min \left(x_{2}{ }^{*}, \operatorname{br}(2)\right)$, where $x_{2} *$ is (13) evaluated at $x_{1}{ }^{*}$. The first term in (17) is the expected deadweight loss in the first remedy period (corresponding to area $\mathrm{G}$ in Figure 2) and the second term is the expected deadweight loss in the second remedy period, discounted to present value.

\footnotetext{
${ }^{19}$ For the same reasons as in the one-remedy-period analysis, the coupon value $r(2)$ that makes the class whole exceeds the markup $m$. But $r(2)$ must be less than the corresponding coupon value in the one-period analysis, $r$, since the availability of a second remedy period is beneficial to consumers, so they would be overcompensated if the coupon value did not decline.
} 
Although we have fully outlined the structure of the two-period model, it is not amenable to an analytical solution because several cases must be considered when deriving the individual's optimal use of coupons in the first and second remedy periods. Moreover, the case that is applicable depends on the coupon value $r(2)$ that makes the class whole. As a consequence, we solved the model computationally in order to determine the deadweight loss when there are two remedy periods. ${ }^{20}$

As noted in the introduction to this section, the deadweight loss from coupons could decrease or increase as the number of remedy periods increases. To illustrate the former possibility, consider again the example discussed in Section $\mathrm{V}$ and suppose that the time discount rate $d$ is .1. In the version of that example in which $\theta=.7$, the deadweight loss declines from $\$ 461.63$ when there is one remedy period to $\$ 305.97$ if there are two remedy periods. If $\theta=.2$, the deadweight loss declines from $\$ 145.69$ to $\$ 29.97$.

One would expect this possibility — that the deadweight loss from coupons declines as the number of remedy periods increases — to be the usual result. For the more remedy periods there are, the greater the opportunity individuals will have to use coupons in future periods to purchase units of the good that they would have purchased anyway (at the competitive price $c$ ), thereby benefiting themselves and reducing the distortion associated with their consumption.

While one might further expect that the deadweight loss would go to zero as the number of remedy periods increases without bound, this is, surprisingly, not the case. To see why, observe that the only way that the deadweight loss can be eliminated is if the individual uses all

\footnotetext{
${ }^{20}$ We do not describe the details of this procedure here because they do not provide any additional insights into our substantive results. The Excel spreadsheet used to perform the calculations referred to in the text is available from the authors at < polinsky@stanford.edu> or < rubinfeld@law.berkeley.edu>.
} 
of his coupons for inframarginal purchases. ${ }^{21}$ However, it will always be optimal for an individual to use some of his coupons for marginal purchases in the first remedy period. To understand this result, note first that, because of time discounting, he will use as many coupons as possible inframarginally - that is, $a_{i}-b c$ coupons - in the first remedy period. But it will not be rational to stop using coupons at that point, while reserving coupons for use in a subsequent remedy period. The reason is that the value of the first marginal coupon (the one used after the first $a_{i}-b c$ coupons) in the first remedy period is just slightly less than the face value of the coupon, whereas the value of a coupon used in a future period is less than this value by a finite amount due to time discounting. Hence, it will always be rational for the individual to use some coupons marginally in the first remedy period regardless of how many subsequent remedy periods there are. It follows that there will always be some deadweight loss under the coupon remedy regardless of the number of remedy periods.

Surprisingly, the deadweight loss from coupons may actually increase when the number of remedy periods is extended from one to two. To illustrate, consider a variation of the example in Section $\mathrm{V}$ in which $a_{L}=\$ 500, a_{H}=\$ 1,000$, and $\theta=.85$ (all other parameter values are unchanged). Given these assumptions, the harm suffered by the class during the injury period is $\$ 4,312.50$. To make the victim class whole with coupons that can be used for only one remedy period would require a coupon value of $\$ 21.29$, and result in a deadweight loss of $\$ 144.42$. If the coupons are allowed to be used for two remedy periods, the coupon value declines to $\$ 18.22$, but the deadweight loss rises to $\$ 160.74$. The deadweight loss increases essentially because it is privately optimal for the consumer to defer many coupons to the second remedy period.

\footnotetext{
${ }^{21}$ By "inframarginal purchases" we mean the purchase of units of the good that would have been bought anyway if the price were the competitive price.
} 
Consequently, although the deadweight loss in the first remedy period declines relative to the one-remedy-period outcome, the additional deadweight loss in the second remedy period more than offsets this (even after discounting).

\section{B. The Discount Remedy}

We will demonstrate that increasing the number of remedy periods from one to two will lead to a lower present value of the deadweight loss under the discount remedy. Let

$s(2)=$ discount below the competitive price when there are two remedy periods.

As seen in Section IV, the benefit to the class if the discount is $s$ for one period is given by (10), and the corresponding deadweight loss is given by (12). By similar reasoning, the benefit to the class if the discount is $s(2)$ for two periods is

$$
(1+D)\left\{\theta\left[\left(a_{L}-b c\right) s(2)+.5 b s(2)^{2}\right]+(1-\theta)\left[\left(a_{H}-b c\right) s(2)+.5 b s(2)^{2}\right]\right\},
$$

and the associated deadweight loss is

$$
.5(1+D) b s(2)^{2} .
$$

We next solve for the $s(2)$ that equates the benefits in the two cases; setting (18) equal to (10) yields the following quadratic equation in $s(2)$ :

$$
\begin{gathered}
.5(1+D) b s(2)^{2}+(1+D)\left(\theta a_{L}+(1-\theta) a_{H}-b c\right) s(2) \\
-\left(\theta a_{L}+(1-\theta) a_{H}-b c\right) s-.5 b s^{2}=0 .
\end{gathered}
$$

It will be useful to rewrite (20), multiplying it by $2 /(1+D) b$, to obtain

$$
\begin{aligned}
& s(2)^{2}+2\left[\left(\theta a_{L}+(1-\theta) a_{H}-b c\right) / b\right] s(2) \\
& \quad-2\left[\left(\theta a_{L}+(1-\theta) a_{H}-b c\right) /(1+D) b\right] s-s^{2} /(1+D)=0 .
\end{aligned}
$$

Two remedy periods will be preferred to one if and only if (19) is less than (12), which is equivalent to

$$
(1+D) s(2)^{2}<s^{2}
$$


To see that this condition holds, assume the contrary, that $(1+D) s(2)^{2} \geq s^{2}$. Then the sum of the first and fourth terms in (21) will be non-negative. Consequently, if (21) is to hold, the sum of the second and third terms must be non-positive. This is equivalent to

$$
s(2) \leq s /(1+D)
$$

If (23) holds, then, squaring each side, it must be true that $s(2)^{2} \leq s^{2} /(1+D)^{2}$. But this contradicts the assumption that $(1+D) s(2)^{2} \geq s^{2}$ since $s^{2} \geq(1+D)^{2} s(2)^{2}>(1+D) s(2)^{2}$. Hence, (22) must hold.

To illustrate the benefit of extending the discount remedy to two periods, reconsider the example from Section $\mathrm{V}$ and assume again that the discount rate $d$ is .1 . If $\theta=.7$, the deadweight loss declines from $\$ 305.51$ when there is one remedy period to $\$ 177.34$ if there are two remedy periods. If $\theta=.2$, the deadweight loss declines from $\$ 403.26$ to $\$ 225.54$.

One might expect that the present value of the deadweight loss would continue to decline as the number of remedy periods is increased. In fact, using the same reasoning as above, and in contrast to the coupon analysis, it is straightforward to demonstrate this result.

The present value of the deadweight loss does not go to zero, however, as the number of remedy periods goes to infinity. This might be surprising because the discount must continuously decline as the length of time it is applicable increases (otherwise, consumers would be overcompensated). But because of time discounting, the discount does not go to zero as the number of remedy periods increases without bound. It follows from this result that the present value of the deadweight loss also does not go to zero.

To see this formally, let $s(n)=$ discount below the competitive price when there are $n$ remedy periods; and $\Sigma(n)=1+D+D^{2}+\ldots+D^{\mathrm{n}}$. 
Then the benefit to the consumers of a discount of magnitude $s(n)$ for $n$ periods is

$$
\Sigma(n)\left\{\theta\left[\left(a_{L}-b c\right) s(n)+.5 b s(n)^{2}\right]+(1-\theta)\left[\left(a_{H}-b c\right) s(n)+.5 b s(n)^{2}\right]\right\} .
$$

Setting (24), the present value of the stream of consumer surpluses for the $n$ periods, equal to the harm during the injury period (3) and solving for $s(n)$ yields:

$$
\begin{aligned}
s(n)=[ & -\Sigma(n)\left(\theta a_{L}+(1-\theta) a_{H}-b c\right) \\
& \left.+\left(\Sigma(n)^{2}\left(\theta a_{L}+(1-\theta) a_{H}-b c\right)^{2}+2 \Sigma(n) b K\right)^{.5}\right] / \Sigma(n) b,
\end{aligned}
$$

where $K$ is defined by (3). The corresponding present value of the deadweight loss is

$$
.5 \Sigma(n) b s(n)^{2} .
$$

The limit of $\Sigma(n)$ is $1 /(1-D)$, which is positive and finite. It is then clear from (24) that the limit of $s(n)$ must be positive; otherwise the benefit to consumers of the discount would go to zero and not make them whole. Hence, the limit of the deadweight loss (26) must be positive. ${ }^{22}$

\section{The Coupon Remedy Versus the Discount Remedy}

When the number of remedy periods is extended from one to two, it is still true that either remedy could be preferable. The reasons are essentially the same as those discussed in Section V above. In the one-remedy-period example there, the discount remedy was preferred when $\theta=$ .7 and the coupon remedy was preferred when $\theta=.2$. These relationships continue to hold in the two-remedy-period analysis. If $\theta=.7$, the present value of the deadweight loss is $\$ 177.34$ under the discount remedy and $\$ 305.97$ under the coupon remedy. But if $\theta=.2$, the present value of the deadweight loss is $\$ 29.97$ under the coupon remedy and $\$ 225.54$ under the discount remedy.

\footnotetext{
${ }^{22}$ Considerations outside of the formal structure of our analysis suggest that it would be problematic to spread the discount over a substantial period of time. First, a firm that was required to charge a price below its marginal cost for a lengthy period would eventually choose to exit the industry. Second, the longer the discount is applicable, the more difficult it becomes to determine the competitive price to which the discount should be applied. Obviously, both of these problems are lessened if the discount remedy is in effect for a relatively short period of time.
} 


\section{Concluding Remarks}

One might wonder why coupon and discount remedies should be considered at all when an apparently better remedy is available — paying cash to the consumers injured by a price overcharge. It is true that a cash remedy would not distort consumption, since the price faced by consumers would not be affected. But a cash remedy can be administratively costly: thousands, perhaps millions, of consumers have to be identified by name and address, and checks have to be sent to them. Note, too, that essentially the same administrative costs would be incurred with the coupon remedy. Thus, a cash remedy generally would be preferable to a coupon remedy since the administrative costs are roughly the same but the cash remedy does not distort consumption. $^{23}$

Even though cash is superior to coupons, the discount remedy might be preferable to cash. The discount remedy does not require identifying the many individuals who were injured by the price overcharge, finding their addresses, and contacting them. Instead, implementation involves imposing and enforcing a price reduction for some specified period of time. Hence, the discount remedy could have lower administrative costs than the cash remedy. But since the cash remedy does not distort consumption, it is preferred on this account. Therefore, whether the discount remedy or the cash remedy is more desirable overall depends on the relative importance of administrative costs and distorted consumption. ${ }^{24}$

${ }^{23}$ If coupons were made fully transferable, they would become equivalent to cash and would not distort consumption. However, a cash remedy still would be preferable in practice because of the transaction costs that consumers would incur in buying and selling coupons.

${ }^{24}$ Another possible remedy would be to make the defendant pay cash to some third party, such as a charitable organization, rather than to the individual plaintiffs. This would accomplish the desired deterrence of the defendant while eliminating the administrative costs of identifying and compensating the plaintiffs. However, 
In comparing the discount remedy and the cash remedy, it also is relevant that the deadweight loss of the discount remedy can be significantly reduced by extending the discount period. In one of the examples in Section VI, the deadweight loss of the discount remedy was $\$ 305.51$ if there is one remedy period and $\$ 177.34$ if there are two remedy periods. In the limit in that example, the deadweight loss goes to $\$ 34.51$. Thus, a discount remedy that is spread over time, even for just a few periods, could be preferable to a cash remedy.

because legal remedies generally are oriented towards compensating victims of wrongful conduct, this type of remedy is rarely used. 


\section{References}

Borenstein, Severin, "Settling for Coupons: Discount Contracts as Compensation and Punishment in Antitrust Lawsuits," Journal of Law and Economics, Vol. 39, No. 2 (October 1996), pp. 379-404..

Gramlich, Fred, "Scrip Damages in Antitrust Cases," The Antitrust Bulletin, Vol. 31, No. 1 (Spring 1986), pp. 261-85.

Gramlich, Fred, "Coupon Remedies in Antitrust Cases: The Form of the Discount Also Matters," Discussion Paper EAG 03-3, Economic Analysis Group, Antitrust Division, U.S. Department of Justice, February 10, 2003.

Leslie, Christopher R., "A Market-Based Approach to Coupon Settlements in Antitrust and Consumer Class Action Litigation," UCLA Law Review, Vol. 49, No. 2 (April 2002), pp. 991-1098.

Miller, Geoffrey P., and Lori S. Singer, "Nonpecuniary Class Action Settlements," Law and Contemporary Problems, Vol. 60, No. 4 (Autumn 1997), pp. 97-154.

Note, "In-Kind Class Action Settlements," Harvard Law Review, Vol. 109, No. 4 (February 1996), pp. 810-27. 